\title{
Helping University Students Succeed At Employment Interviews: The Role Of Self-Reflection In E-Portfolios
}

\section{ABSTRACT}

In the context of a Transition to Work course for fourth-year psychology majors, we had students use an e-portfolio to self-reflect on the learning experiences they deemed most significant during their degree. Such significant learning experiences can be drawn upon when answering behavioral job interview questions. We examined whether students would show improvement in mock behavioral interview performance over time, and whether any potential improvement was related to performance on self-reflective course assignments. Students indicated that the majority of their significant learning experiences had taken place outside of the classroom (e.g., paid and unpaid work, extracurricular activities). Across the duration of the course, students improved on all metrics of interview performance, and final interview performance was predicted by student grades on a self-reflective e-portfolio, but not other course assignments.

\section{KEYWORDS}

e-portfolio, behavioral interview, university students, self-reflection

More now than in the past, universities are charged with educating students with diverse backgrounds and aspirations (Kift \& Nelson, 2005), with career advancement as one of the primary motivators for attendance (Côté \& Levine, 1997; Phinney, Denis \& Osorio, 2006). Thus, universities have had to modify their curricula to meet the needs of these modern learners. Curriculum reform requires the explicit articulation of desired student outcomes. In addition to content knowledge, some educational bodies have outlined 'graduate attributes' or 'essential learning outcomes' for all university graduates, regardless of major (e.g., Association of American Colleges \& Universities, 2016; Oliver, 2013). Some universities include personal development planning in their curriculum, which involves student self- and career-reflection (Doig, Illsley, McLuckie \& Parsons, 2006) and both the American Psychological Association's (APA) Guidelines for the Undergraduate Psychology Major and the Ontario Universities Council on Quality Assurance include learning goals that focus on professional development.

These curriculum additions may be somewhat difficult to integrate into traditional contentbased course work. The introduction of final-year capstone courses that amalgamate across degree experiences may provide space in the curriculum for such goals to be achieved. Here we describe the introduction of a Transition to Work (TtW) Psychology capstone course for non-honors Psychology majors and explore how successful it is at improving students' job interview performance over time and whether the inclusion of assignments designed to promote self-reflection encourages improved interview performance. Thus, we are assessing one way such TtW capstone courses may help non- 
honors students achieve the professional and career development goals of the APA and other educational associations.

The present Transition to Work course included a number of assignments that were explicitly designed to promote students' self-reflection about their self-reported significant learning experiences. The American Association of Colleges and Universities has indicated that some post-secondary learning experiences are likely to be more influential than others. Called 'high impact practices' these forms of teaching and learning have been demonstrated to improve students' learning, as well as increase engagement and retention across diverse student populations (Kuh, 2008). They include such things as undergraduate research experiences, learning communities, capstone courses, experiential learning (including experiences with diverse groups), writing-intensive courses, and the opportunity to participate in collaborative projects.

More recently, however, Kuh (2010) has pointed out that significant learning experiences during the college years need not be confined to course-based activities. Indeed, the current cohort of undergraduates often manage course-related demands with multiple co-curricular responsibilities, including paid or volunteer work in the community, and on-campus activities (e.g., student government, clubs or sports teams). It has been further argued that for many students it is these co-curricular experiences that provide the most significant learning, and that it is important to help students to integrate the learning that occurs in the formal curriculum with that which is happening in the cocurriculum (Bass, 2012; Kuh, 2010).

In the present study, we were interested in examining nearly-graduated students' perceptions of the most significant learning experiences that they had had during the course of their degree. We reasoned that these would be the experiences that would provide the greatest impetus for self-reflection, and would be the ones that students would be most likely to draw upon during interviews with employers. We anticipated that student reports of their most significant learning experiences would include those drawn from both the formal curriculum and the co-curriculum. Owing to a lack of empirical data, however, we did not make any predictions about which of these types of experiences would be reported most frequently.

\section{Self-reflection and interview performance}

Self-reflection is positively related to general academic performance (Cleary et al., 2015; Travers, Morisano \& Locke, 2015) and is key to developing important career-relevant skills (Yancey, 1998). Self-reflection may also be important to improve the interview skills of recent university graduates. In support of this idea, naturally-occurring individual differences in career-related selfreflection predicted graduate students' interview performance and subsequent job offers (Stumpf, Austin \& Hartman, 1978). This finding leaves open the possibility that purposefully encouraging selfreflection skills among nearly-graduated university students may improve job interview performance by enhancing their ability to leverage key learning experiences in response to behavioral interview questions.

Employers are increasingly using behavioral interview techniques to assess the competencies of prospective employees (US Department of Education, 2015). Behavioral interviewers use lines of questioning that encourage candidates to reflect on key learning experiences and to give specific examples of how they have demonstrated a relevant skill set, or dealt with challenges. For instance, interviewees may be asked to describe a time when they demonstrated excellent leadership ability, or how they managed conflict with a co-worker (Browning \& Cunningham, 2012; Cook, 2013). 
To address such questions effectively, recent graduates need to draw on learning experiences that they deem significant, and that are related to the behavioral question being asked. In addition, they need to communicate their answers to such questions in such a way as to clearly demonstrate that they do possess the skill in question. Using the STAR interview technique helps to accomplish these goals (Connaughton \& Edgar, 2011). STAR is an acronym for 'Situation/Task', 'Action', and 'Result', and each of these three areas should be included in every response to a behavioral interview question. Specifically, interviewees should provide context by describing a particular situation they were in or task they had to accomplish, what actions they took to achieve their goal (including the skills they employed), and the result or outcome of the situation. It is important to note, however, that it is not sufficient for interviewees to simply address each of these three areas. Job recruiters' decisions are impacted by the candidate's communication skills (Curhan \& Pentland 2007; Graves \& Karren, 1992). Answers must be clear, complete, and on-topic (Farr, 2005).

In the present study, we hypothesized that students would provide better answers to behavioral interview questions at the end of the TtW course than they had at the beginning, owing to the opportunity to reflect on significant learning experiences during the course. We further hypothesized that their performance on self-reflective assignments (though not a non-reflective assignment) would be associated with the amount of improvement in their interview scores.

\section{Transition to Work (TtW) course}

The TtW course is a required 12-week capstone course designed for those students who are completing a four-year degree in psychology, but who are not completing an honors thesis project. The primary goal of the course is to provide a space in the degree program for students to reflect on the curricular and co-curricular learning experiences they have had, and to consider how those experiences have contributed to their transferable skills, as well as their understanding of themselves. In-class lectures and activities focused on helping students to recognize and articulate their career-relevant skill set, with a particular focus on communication, critical thinking, problem solving, collaboration, interview skills, and self-assessment. Students completed three main assignments. One (career wiki) was designed to further their understanding of a career that they were interested in pursuing and the online resources that would be helpful in guiding career-related research. The other two assignments (LinkedIn profile, integrated learning e-portfolio) were specifically designed to promote self-reflection concerning students' careerrelevant skills and abilities.

\section{Career wiki}

Students completed a job profile for the department's What can you do with a degree in psychology? wiki. To increase the relevance of this assignment, students were encouraged to write their wiki entries about a job they were personally interested in, and each student wrote about a different job. Each student's wiki entry included a general overview of the job, as well as a description of job duties and responsibilities, a typical workday, educational requirements and other qualifications, related skills, the relevance of a psychology degree, salary potential, and projected job demand. These assignments were graded for the inclusion of the relevant content, as well as for writing style and grammar. Students were not specifically required to engage in self-reflection during this assignment.

\section{Linkedln profile}

LinkedIn is a professional networking website that is increasingly used by employers to recruit new talent. Users create profiles and build professional connections by following the online activities of 
other users and companies. They can also search for jobs on this website. In the TtW course we asked students to complete a LinkedIn profile, which included information on their skills, abilities, previous work experience and career goals. This assignment was designed to promote self-reflection; as such, an independent evaluator graded these profiles holistically for cohesiveness, professionalism, and the use of self-reflective content.

\section{Integrated learning e-portfolio}

Students developed a personal webpage that functioned as an e-portfolio. On their website, students described five key learning experiences from a variety of areas (e.g., academic or non-academic courses, paid or volunteer work, travel, sports teams, etc.). We asked students to categorize each learning experience as related to one of the following: course-based experiences, paid work, volunteer work, extracurricular activities, leisure-based experiences, and personal development experiences. For each experience, students documented its importance, the tasks that they were responsible for, the skills that they developed, and the lessons they learned. Other aspects of the e-portfolio included a homepage that described students' personal philosophy (i.e., the values and goals that motivate them), and an endpage that described their plans for ongoing learning (i.e., skills or personal characteristics they wished to further develop and their plans for doing so). Like the LinkedIn profile, this assignment was designed to promote self-reflection. It was completed in stages to provide students with feedback about the selfreflective content to be included on the website.

The use of e-portfolios in university courses is increasing in popularity. Theoretical reasons for the use of e-portfolios include increased reflection (Doig et al., 2006; Eynon, Gambino \& Török, 2014; Landis, Scott, \& Kahn, 2015) and increased integration of knowledge (Eynon et al., 2014; Peet et al., 2011), among other benefits. In the TtW course we hoped that students would benefit from such selfreflection, and hypothesized that performance on the e-portfolio would predict improvements in behaviorally-based interview performance over time.

\section{Mock employment interview}

In addition to the three assignments, students videotaped their responses to a series of behavioral interview questions at the beginning and end of the course. This assignment is detailed more thoroughly in the Procedure. Performance on these interviews was of interest to us as an outcome variable. Such interview performance allowed us one way to assess whether our capstone course was helping the University's psychology program meet the goals of the APA and other educational associations.

Many software programs are now available for such electronic mock interviews, and both electronic mock interviews and face-to-face mock interviews have been shown to increase student confidence and success at interviews (Baur et al., 2013; Hansen, Oliphant, Oliphant, \& Hansen, 2009).

\section{The current study}

In the present study, we investigated the nature of the learning experiences that senior undergraduates deemed to be significant, with the assumption that these would be the ones they would be most likely to draw upon when asked behavioral interview questions by a potential employer. Second, we examined the extent to which an undergraduate course focused on reflection about those learning experiences vis-à-vis the transition to work would improve students' ability to answer behaviorally-based interview questions between the early and later stages of the course. In this regard, we focused on improvement in two domains: content (use of the STAR technique) and communication (articulation, 
completeness and the degree to which responses were on-topic). Finally, we were interested in establishing whether any potential improvement in interview performance was related to performance on course-based assignments, some of which were designed to promote self-reflection.

\section{METHOD}

\section{Participants}

Seventy-one students (22 male, 55 Caucasian) completed the TtW course involving the three assignments and two mock employment interviews. With regard to our assessment of significant learning experiences, 68 students handed in a preliminary assignment for the e-portfolio that asked them to reflect on eight significant learning experiences and indicate the domain in which the experience took place (e.g., a course for credit, paid work, extracurricular activities).

In terms of our assessment of interview performance, students who did not complete all of the assignments $(n=6)$, failed to take the mock employment interview seriously $(n=2)$ or who completed the same interview questions on both occasions $(n=3)$ were excluded from the analyses, resulting in a total sample size of 60 students.

\section{Measures and procedure}

Significant learning experiences

As part of the creation of the integrated learning e-portfolio, students were initially asked to reflect on eight of the most significant learning experiences that they had had while completing their degree (the final website incorporated five of these experiences). Students were encouraged to think broadly about their learning, and were told that they could include experiences from wherever they believed learning to have occurred: courses, paid or unpaid work, extracurricular activities, personal experiences, etc. While we listed more categories of experiences including the co-curriculum than the formal curriculum, we were not worried that this would bias their responding, given the quantity of time spent engaged in course-related activities. Students spend approximately 15 hours in class each week, and an additional 17 hours studying (Pierre, 2014), therefore, we felt that they would have ample experiences to draw from in this regard.

\section{Evaluator ratings of interview performance}

The primary measure of students' ability to respond to skill-based interview questions was the quality of their oral responses to the mock employment interview questions. These short mock interviews were conducted using Interview Stream, an online tool that was purchased for use at the University where the data were collected. Interview Stream is increasingly being utilized by Career Services departments at post-secondary institutions, as well as by employers who are interested in screening job applicants (e.g., Rockawin, 2012). The course instructor selected from a large bank of interview questions, and defined the parameters of the students' experience with the tool (e.g., how long they had to answer each question). At the beginning of the course, the instructor created three mock interviews in Interview Stream, each with four questions. These 12 questions focused mainly on the students' transferable skills (e.g., communication, problem solving, teamwork) and included behavioral interview questions that asked students to describe a specific event that provided evidence of the student's competence in a particular skill area (e.g., "Give an example of a time when you had to work together with a team of people and that team was not working very well together. What did you do?").

As part of the course requirements, students completed a mock interview using the Interview Stream tool during the second week of classes (baseline interview) and a second, different, interview 
during the tenth week of classes (final interview). Creating three interviews helped to minimize the likelihood that students would simply pass the interview questions to their classmates, and so that we could have students complete different baseline and final interviews to avoid practice effects. The interviews were roughly equivalent in terms of the difficulty of the questions and the content covered (see Preliminary Analyses section).

Completing the interview involved students first viewing a short video clip of a female interviewer sitting in an office. The interviewer asked the first question selected by the instructor and the webcam began videotaping the student's response to the question. A timer on the screen told students how long they had to complete their answer; if they finished before the time was up, they could stop the recording. Having completed the first question, another video of the female interviewer appeared, during which she asked the second question selected by the instructor. Students were videotaped again as they answered, and this process continued until all of the questions were answered.

At the end of the course all of the baseline and final interviews were viewed by an experienced evaluator (not the course instructor or teaching assistant) who assessed students' overall performance on the four interview questions in five categories: two measures of their use of the STAR technique (inclusion of any of the three aspects of STAR-Situation/Task, Action, Result within and across questions), their articulation, the completeness of their response and the extent to which the response was on-topic. The evaluator was blind to time; that is, they were unaware which interviews were baseline and which were final, in addition to being blind to our hypotheses.

Each of the four interview questions was scored separately on these five categories and totals were created for both the four baseline interview questions and the four final interview questions. Several variables were of interest with respect to our goal of examining change over time in students' interviewing ability. Specifically, with respect to the use of the STAR technique we evaluated how many of the four questions had some reference to one or more STAR components (maximum of 4 for each interview) and how many of the three STAR components were mentioned across all questions (maximum of 12 for each interview). Thus, there were two separate measures of their use of the STAR technique.

With respect to communication, articulation, completeness and on-topic categories were scored out of 3 for each of the four questions; thus, we computed total articulation scores (maximum of 12 for each interview), total completeness scores (maximum of 12 for each interview), and total on-topic scores (maximum of 12 for each interview).

\section{Peer ratings}

Peers were randomly assigned to evaluate two of their colleagues' final interviews. The following three dimensions from the peer evaluation were of particular interest because parallel measures were included in the evaluator ratings, thus allowing for an approximation of inter-rater reliability:

(a) Did the student speak in an articulate manner and integrate professional language?

(b) Did the student integrate knowledge, content, and experiences?

(c) Did the student answer the question that was presented?

Peers gave their colleagues a score out of four on each dimension. The two peers' ratings were then averaged together. 


\section{Course assignments}

Students completed the three additional assignments described in the Introduction over the course of the semester. The e-portfolio and career wikis were both due at the end of the semester and the LinkedIn profile was completed two weeks into the semester. These were graded by the teaching assistant for the course, who was not the same individual evaluating interview performance.

\section{Ethics}

This project adheres to the ethics guidelines outlined in the Declaration of Helsinki, and was approved by the Brock University Research Ethics Board.

\section{RESULTS}

\section{Preliminary analyses}

Medium to strong zero-order correlations were observed between scores on the five evaluator interview dimensions at both Time 1 (mean inter-item correlation $=.55$; range $=.33$ to .68$)$ and Time 2 (mean inter-item correlation $=.50$; range $=.04$ to $.73 ; 1$ of 10 correlations ns); therefore, repeated measures multivariate analyses of variance (MANOVAs) were used for further analyses.

Two MANOVAs were carried out to confirm that the three interviews set up by the course instructor appeared to be of equivalent difficulty. The dependent variables were the five Time 1 and Time 2 evaluator's scores, and the independent variable was the interview that was completed. At Time 1, performance on the interview did not differ across the three interviews (all $F s<2.03$, all $p s>.14$ ). However, at Time 2 , the interviews differed in the total articulation score $(p=.02-$ version $\mathrm{C}$ significantly lower than versions A and B; all other $F \mathrm{~s}<.9$, all other $p$ s $>.39$ ). Thus, caution should be taken interpreting the results of the articulation score in the main analyses. Given that none of the other metrics were significantly different across interview types (including the composite measures of overall STAR performance), and no one interview showed consistently poor or superior performance, we are not concerned that the use of the three interviews introduced systematic noise into our analyses.

While we are unable to provide inter-rater reliability statistics for interview performance, such values can be approximated by comparing peer ratings with evaluator ratings. Averaged peer responses to the question "Did the student integrate knowledge, content and experiences?" correlated with the evaluator's assessment of the number of STAR components covered at .27, $p=.05$, and the evaluator's assessment of the completeness of the response at .28, $p=.04$. Peer assessments of "Did the student answer the question that was presented?" correlated with the evaluator's assessment of the on-topic nature of the response at .50, $p<.001$. Peer ratings of "Did the student speak in an articulate manner and integrate professional language?" correlated with the evaluator's assessment of the articulation of the response at .32, $p=.02$. Therefore, we have confidence that our coder provided accurate assessments of the students' interview performance.

The two peers' ratings agreed moderately with one another, with correlations ranging from .10 to .36 on the three dimensions, with the highest peer agreement on the question "Did the student speak in an articulate manner and integrate professional language?" Peers were not trained to do such ratings, and so we did not expect overly high inter-peer or high peer-evaluator agreement.

\section{Student perceptions of significant learning experiences}

A total of 534 significant learning experiences were coded by the students themselves into one of six categories, after which we calculated the percentage of experiences that fell into each category. The categories of learning experiences included: course-based experiences related to completion of the 
degree (25\%), paid work (23\%), volunteer work (19\%), extracurricular activities (10\%), leisure-based experiences (e.g., organizing a knitting group or travelling abroad; 4\%) and personal development (20\%). The personal development category captured a wide array of experiences; some examples included students' descriptions of how they coped with the death of a friend or family member, told friends and family members that they were gay, or managed the responsibilities associated with moving away from home for the first time.

\section{Change in interview performance over time}

A one-way MANOVA was run to determine whether the five metrics of interview performance (the two measures of the use of the STAR technique, articulation, completeness and on-topic) changed over time. Both the multivariate $F$ test $(F(5,55)=12.30, p<.001)$ and univariate follow-up tests (all $F_{s}(1,59) \geq 17.23$, all $\left.p s<.001\right)$ provide support for significant improvement on all dimensions over time. Means and standard deviations are provided in Table 1.

Table 1. Change in interview performance over time

\begin{tabular}{lll}
\hline & $\begin{array}{l}\text { Baseline Interview } \\
\text { Mean(SD) }\end{array}$ & $\begin{array}{l}\text { Final Interview } \\
\text { Mean(SD) }\end{array}$ \\
\hline $\begin{array}{l}\text { Number of questions / } 4 \text { with at least one reference to } \\
\text { STAR }\end{array}$ & $2.95(0.83)$ & $3.63(0.58)$ \\
Number of STAR components covered /12 & $4.8(1.96)$ & $6.57(1.86)$ \\
Articulation /12 & $8.37(2.18)$ & $9.52(1.63)$ \\
Completeness of response /12 & $8.75(1.94)$ & $10.25(1.46)$ \\
On-topic /12 & $8.6(1.87)$ & $10.52(1.35)$ \\
\hline
\end{tabular}

\section{Predictors of improvement in interview performance over time}

Students who performed well at both the baseline and final interviews were also the students who performed well on the course assignments designed to promote self-reflection. Descriptive statistics are presented in Table 2 and Pearson $r$ correlations are presented in Table 3. Notably, grades on the assignments designed to promote self-reflection (LinkedIn profile and ILP e-portfolio) were most strongly correlated with various aspects of Interview Stream performance at both interviews.

\section{Table 2. Assignment descriptive statistics}

\begin{tabular}{lllll}
\hline & Min & Max & Mean & SD \\
\hline LinkedIn /10 & 0 & 9.50 & 7.73 & 2.18 \\
ILP e-portfolio /15 & 0 & 14.63 & 11.08 & 2.08 \\
Wiki /68 & 26 & 60.50 & 50.0 & 6.15 \\
\hline
\end{tabular}


Table 3. Interview Stream performance and self-reflection assignment correlations

\begin{tabular}{|c|c|c|c|c|c|c|c|c|}
\hline & 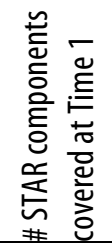 & 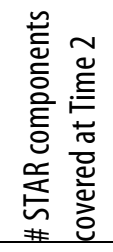 & 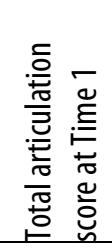 & 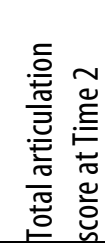 & 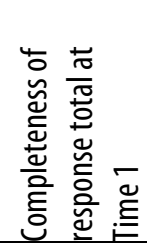 & 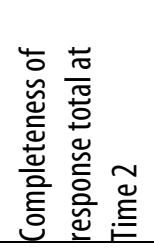 & 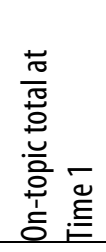 & 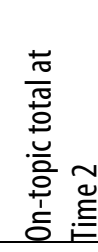 \\
\hline LinkedIn profile & $.26^{*}$ & $.28^{*}$ & $.27^{*}$ & .23 & .24 & .19 & $.31^{*}$ & $.41^{* *}$ \\
\hline ILP e-portfolio & .24 & $.41^{* *}$ & $.33^{* *}$ & $.31^{*}$ & .22 & $.38^{* *}$ & .06 & .22 \\
\hline Wiki & $.37^{* *}$ & .23 & $.29^{*}$ & .18 & .15 & .18 & .12 & .23 \\
\hline
\end{tabular}

${ }^{*}$ Correlation is significant at the 0.05 level (2-tailed).

${ }^{* *}$ Correlation is significant at the 0.01 level (2-tailed).

Note: For conciseness only the overall STAR composite values are presented here.

We were additionally interested in whether performance on the self-reflective assignments would predict positive change in Interview Stream performance. To examine this question, we created a grand interview score for baseline and final interviews by summing $z$-scored communication (articulation, completeness, and on-topic scores) with $z$-scored STAR totals. Overall final interview scores were then regressed on individual course assignment grades, after controlling for overall baseline interview scores in an initial regression model. Results of this analysis indicated that only performance on the integrated learning e-portfolio predicted final interview performance (after controlling for initial interview performance; $\left.\mathrm{R}^{2}=.32 ; F(4,55)=6.39 ; p<.001\right)$. See Table 4 .

Table 4. Self-reflective assignment performance as predictors of final interview performance

\begin{tabular}{llllll}
\hline \multirow{2}{*}{ Model } & Variable & \multicolumn{4}{c}{ Final grand interview scores } \\
\cline { 3 - 6 } & Constant & $\mathrm{B}(\mathrm{SE})$ & $\mathrm{B} 95 \% \mathrm{Cl}$ & $\mathrm{t}$ & $\mathrm{p}$ \\
\hline \multirow{2}{*}{2} & $0.18(0.21)$ & {$[-0.23,0.60]$} & 0.88 & .38 \\
& Baseline grand interview score & $0.38(0.11)$ & {$[0.15,0.61]$} & 3.36 & $<.001$ \\
\hline & Constant & $-3.27(1.77)$ & {$[-6.82,0.28]$} & -1.84 & .07 \\
& Baseline grand interview score & $0.27(0.11)$ & {$[0.04,0.50]$} & 2.34 & .02 \\
& LinkedIn & $0.19(0.11)$ & {$[-0.03,0.41]$} & 1.70 & .09 \\
& ILP e-portfolio & $0.28(0.10)$ & {$[0.08,0.48]$} & 2.79 & .01 \\
& Wiki & $-0.02(0.04)$ & {$[-0.10,0.05]$} & 0.59 & .56 \\
\hline
\end{tabular}

\section{DISCUSSION}

In the present study, we had fourth-year psychology students who were enrolled in a Transition to Work course complete two assignments with self-reflective content, one without self-reflective content, as well as two online behavioral interviews. We were interested in examining the types of learning experiences that senior psychology majors found significant, as these were likely the experiences that they would draw on in behavioral interviews. We also wished to determine whether students' interview performance improved from the beginning of the course to its end, and whether any 
improvement would be associated with grades on self-reflective course assignments. Each of these questions will be addressed in turn.

\section{Student perceptions of significant learning experiences}

When asked to outline eight of their most significant learning experiences, senior psychology majors provided examples that cut across both the formal and co-curriculum. However, more than half (52\%) of the experiences described would most appropriately be viewed as co-curricular (paid and unpaid work; extracurricular activities), while only one quarter came from the formal curriculum. These data provide some preliminary support for Bass' (2012) assertion that the current cohort of college students find greater value in the activities undertaken outside of their classes. Why might this be the case? It is possible that students find it easier to see the relevance of co-curricular activities to the "real world" in which they will have to live and work, and consequently believe that such experiences are more meaningful. Indeed, past research has suggested that students evaluate course-based assignments as being only moderately relevant, and this finding may reflect the fact that they often do not spontaneously recognize how those assignments foster skills that are transferable to their personal and professional lives (Martini, Rail, \& Norton, 2015). Universities should develop ways to increase the actual and perceived relevance of course work. Suggestions include having faculty explicitly state the career-related skills that their course-based work is intended to foster and to emphasize the skills that are in demand by employers (Martini et al., 2015). Other strategies include increasing the relatedness felt by students; that is, increasing their sense of "what does this have to do with me?" (Roberson, 2013). Part of relatedness includes the students' relationship with the faculty member, as students are more likely to see content as relevant when it is delivered by a likeable faculty member (Ryan \& Deci, 2000). Relatedness can be increased through ice-breakers and student reflection assignments (Roberson, 2013).

Somewhat unexpected was the large proportion (20\%) of learning experiences that related to personal development. These experiences were often linked to strong emotions and were viewed by students as helping them transition from late adolescence to adulthood. While such experiences do not often appear in accounts of learning in post-secondary education, they have been covered extensively in the developmental literature related to emerging adulthood (Arnett, 2015). Universities can take strides to link learning experiences with personal development more closely, capitalizing on a process that our data suggest is occurring already for some students. Work placements have been shown to relate to undergraduates' emotional growth (Eden, 2014), and universities could offer more of these to facilitate this important development. Cartney and Rouse (2006) suggest that successful small-group work fosters a sense of identity and belonging key to emotional development. Thus, pedagogic practices can not only offer cognitive and utilitarian (work-related) gains, but can also facilitate affective experiences that may lead to greater emotional maturity. Additional research that examines the factors that predict student perceptions about the significance of learning experiences from the curricular, co-curricular and personal domains would be helpful in advancing our understanding of this area.

\section{Changes in interview performance over time}

Students did show significant improvement in interview performance over time in all domains assessed (i.e., the STAR and communication metrics). Their answers contained more behaviorally relevant information and were articulated more clearly. These effects cannot be attributed solely to practice effects (as students did not complete the same interview twice), nor can these effects be attributed to evaluator feedback (since none was provided to students after the baseline interview). 
However, it is possible that our results are attributable to practice effects of repeated exposure to online interviews in general (rather than practice effects associated with repeated exposure to the same questions). Thus the main effect of time could be somewhat influenced by a general practice effect.

We believe that the self-reflective assignments completed during the course may have been helpful in fostering improvements in interview performance because they required students to reflect on, and write about, their significant learning experiences in a manner that is consistent with STAR-based answers to behavioral interview questions. Specifically, these assignments required that students describe their experiences (situation/task), what they were responsible for doing in that context and the skills they used (action) and what they learned from the outcome of the experience (result). In keeping with this idea, grades on the self-reflective assignments were correlated with various metrics of interview performance. Further, grades on the integrated learning e-portfolio assignment predicted final interview scores, even after controlling for baseline interview scores. While both the LinkedIn and the e-portfolio assignments were intended to foster self-reflection, we believe that the LinkedIn profile may not have prompted the same depth of self-reflective thinking that was required for the e-portfolio because it was completed in a much shorter timeframe. Specifically, the LinkedIn assignment was completed during the first two weeks of class, whereas the e-portfolio was completed in stages across the entire semester. In addition, students were given feedback on the quality of their writing and thinking at several stages during the completion of the e-portfolio, which likely helped to deepen their self-reflection.

\section{Limitations and future directions}

The conclusions that we have drawn in this study must be tempered by its limitations. First, this study is limited by the fact that its participants come from a single university; additional research is needed to determine whether the present findings would generalize to students attending other postsecondary institutions.

Additional research might also help to clarify the specific parameters of the e-portfolio that were most important in promoting improvements in students' mock interviews (e.g., completion over an extended timeframe; extensive feedback on writing), or shed light on other self-reflective assignments that could further their interview skills. For example, researchers might ask recruiters to determine whether or not they would hire the individual after both their baseline and final interviews to determine whether repeated practice increases the likelihood of obtaining employment. Such an extension of the present study would also clarify whether the changes observed in interview performance over time are of practical (as well as statistical) significance.

Moreover, systematically examining changes in the nature or amount of self-reflective content would also be instructive. While it is clear that student performance was linked to self-reflection on significant learning experiences, perhaps domain-specific self-reflection about their own interview performance could magnify these effects. Self-assessments after each interview could be added.

Further, in order to eliminate the possibilities that

1. a general practice effect of exposure to online interviews, or,

2. some maturational effect over the academic term is responsible for the main effect of time, the inclusion of a comparison group could be instructive. For instance, students who are not enrolled in this course could be asked to perform the same interviews on two occasions as a point of comparison. Without this, the size of the practice effect is difficult to estimate. Additionally, without a comparison group and some objective measure of self-reflective skills, we cannot know if completing the e-portfolio led to direct change in self-reflection. 


\section{CONCLUSIONS}

These limitations notwithstanding, our findings suggest that undergraduate students believe that their most meaningful learning is derived from a variety of experiences that include the formal and co-curriculum, as well as events in their personal lives. A course designed to promote self-reflection concerning these activities appears to be helpful in improving students' abilities to address behavioral interview questions, though it may be the case that only longer-term self-reflective assignments that include feedback will foster better interview performance. We believe that our results offer some interesting preliminary data for instructors who are concerned with enhancing undergraduates' ability to perform well in interviews with potential employers and articulate their skill set in a comprehensive and compelling manner.

\section{ACKNOWLEDGEMENTS}

We would like to thank Ashley Rail for her assistance in data analysis and coding.

Christine L. Lackner is now at the Psychology Department, Mount St. Vincent University, Canada.

Tanya Martini is with the Psychology Department, Brock University, Canada.

\section{REFERENCES}

American Psychological Association. (2013). APA guidelines for the undergraduate psychology major: Version 2.0. Retrieved from http://www.apa.org/ed/precollege/undergrad/index.aspx

Arnett, J. J. (Ed.). (2015). The Oxford handbook of emerging adulthood. New York, NY: Oxford University Press. Bass, R. (2012). Disrupting ourselves: The problem of learning in higher education. Educause Review, 47(2), 23-33.

Baur, T., Damian, I., Gebhard, P., Porayska-Pomsta, K., \& André, E. (2013, September). A job interview simulation: Social cue-based interaction with a virtual character. In Social Computing (Socia/Com), 2013 IEEE International Conference (pp. 220-227).

Browning, B. W., \& Cunningham, J. R. (2012). Students better be on their best behavior: How to prepare for the most common job interviewing technique. Communication Teacher, 26(3), 152-157. doi: $10.1080 / 17404622.2011 .650700$

Cartney, P. \& Rouse, A. (2006). The emotional impact of learning in small groups: highlighting the impact on student progression and retention. Teaching in Higher Education, 11(1), 79-91. doi: $\underline{10.1080 / 13562510500400180}$

Cleary, T. J., Callan, G. L., Malatesta, J., \& Adams, T. (2015). Examining the level of convergence among selfregulated learning microanalytic processes, achievement, and a self-report questionnaire. Journal of Psychoeducational Assessment, 33(5), 439-450. doi: $10.1177 / 0734282915594739$

Connaughton, J., \& Edgar, S. (2011). Framework for reflective practice. Focus on Health Professional Education, 12(3), 89-93.

Cook, S. G. (2013). Behavioral interviews: Hire for the competencies needed. Women in Higher Education, 22(3), 23-24. doi: $10.1002 /$ whe.10437

Cote, J. E., \& Levine, C. (1997). Student motivations, learning environments, and human capital acquisition: Toward an integrated paradigm of student development. Journal of College Student Development, 38, 229-243.

Curhan, J. R., \& Pentland, A. (2007). Thin slices of negotiation: predicting outcomes from conversational dynamics within the first 5 minutes. Journal of Applied Psychology, 92(3), 802. doi: 10.1037/0021-9010.92.3.802

Doig, B., Illsley, B., McLuckie, J., \& Parsons, R. (2006). Using ePortfolios to enhance reflective learning and development. Handbook of research on ePortfolios, 158-167.

Eden, S. (2014). Out of the comfort zone: Enhancing work-based learning about employability through student reflection on work placements. Journal of Geography in Higher Education, 38(2), 266-276.doi: $10.1080 / 03098265.2014 .911826$

Eynon, B., Gambino, L. M., \& Török, J. (2014). What difference can ePortfolio make? A field report from the 
connect to learning project. International Journal of ePortfolio, 4(1), 95-114. Retrieved from http://www.theijep.com/pdf/JJEP127.pdf

Farr, M. (2005). Next-day job interview: How to prepare tonight and get the job tomorrow. Indianapolis, IN: Jist Publishing.

Graves, L. M., \& Karren, R. J. (1992). Interviewer decision processes and effectiveness: An experimental policycapturing investigation. Personnel Psychology, 45(2), 313-340.

Hansen, K., Oliphant, G. C., Oliphant, B. J., \& Hansen, R. S. (2009). Best practices in preparing students for mock interviews. Business Communication Quarterly, 72(3), 318-327. doi: 10.1177/1080569909336951

Kift, S. M. \& Nelson, K. J. (2005). Beyond curriculum reform: Embedding the transition experience. http://conference.herdsa.org.au/2005/pdf/refereed/paper_294.pdf

Kuh, G. (2010, November 20). Maybe experience really can be the best teacher. Chronicle of Higher Education. Retrieved July 10, 2014, from http://chronicle.com/article/Maybe-Experience-Really-Can-Be/125433/

Kuh, G. D. (2008). High-Impact Educational Practices: What They Are, Who Has Access to Them, and Why They Matter. Washington, DC: Association of American Colleges and Universities.

Landis, C. M., Scott, S. B., \& Kahn, S. (2015). Examining the role of reflection in ePortfolios: A case study. International Journal of ePortfolio, 5(2), 107-121.

Martini, T. S., Rail, A., \& Norton, C. (2015). Psychology students' understanding of the skill-based learning fostered through university assignments. Teaching of Psychology, 42, 335-338. doi: 10.1177/0098628315603182

Oliver, B. (2013). Graduate attributes as a focus for institution-wide curriculum renewal: Innovations and challenges. Higher Education Research \& Development, 32(3), 450-463. doi: 10.1080/07294360.2012.682052

Ontario Universities Council on Quality Assurance (2016). OCAV's Undergraduate and Graduate Degree Level Expectations. Retrieved from http://oucqa.ca/framework/appendix-1

Peet, M., Lonn, S., Gurin, P., Boyer, K. P., Matney, M., Marra, T., ... \& Daley, A. (2011). Fostering integrative knowledge through ePortfolios. International Journal of ePortfolio, 1(1), 11-31.

Phinney, J. S., Dennis, J., \& Osorio, S. (2006). Reasons to attend college among ethnically diverse college students. Cultural Diversity and Ethnic Minority Psychology, 12(2), 347. doi: 10.1037/1099-9809.12.2.347

Pierre, K. (2014, August). How much do you study? Apparently 17 hours a week is the norm. USA Today College. Retrieved from http://college.usatoday.com/2014/08/18/how-much-do-you-study-apparently-17hours-a-week-is-the-norm/

Roberson, R. (2013). Helping students find relevance. American Psychological Association. Retrieved from http://www.apa.org/ed/precollege/ptn/2013/09/students-relevance.aspx

Rockawin, D. (2012). Using innovative technology to overcome job interview anxiety. Australian Journal of Career Development, 21(2), 46-52.

Ryan, R. M., \& Deci, E. L. (2000). Self-determination theory and the facilitation of intrinsic motivation, social development, and well-being. American Psychologist, 55, 68-78.

Stumpf, S. A., Austin, E. J., \& Hartman, K. (1984). The impact of career exploration and interview readiness on interview performance and outcomes. Journal of Vocational Behavior, 24(2), 221-235.

The Association of American Colleges and Universities. (2016). Trends in Learning Outcomes Assessment. Retrieved from https://www.aacu.org/publications

Travers, C. J., Morisano, D., \& Locke, E. A. (2015). Self-reflection, growth goals, and academic outcomes: A qualitative study. British Journal of Educational Psychology, 85(2), 224-241. doi: 10.1111/bjep.12059

US Department of Education, National Center for Education Statistics (2015). The Condition of Education 2015 (NCES 2015-144). National Center for Education Statistics. Washington, DC.

Yancey, K. B. (1998). Getting beyond exhaustion: Reflection, self-assessment, and learning. The Clearing House, 72(1), 13-17.

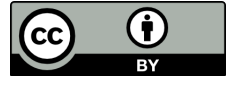

Copyright for the content of articles published in Teaching \& Learning Inquiry resides with the authors, and copyright for the publication layout resides with the journal. These copyright holders have agreed that this article should be available on open access under a Creative Commons Attribution License 4.0 International (https://creativecommons.org/licenses/by/4.0). The only constraint on reproduction and distribution, and the only role for copyright in this domain, should be to give authors control over the integrity of their work and the right to be properly acknowledged and cited, and to cite Teaching \& Learning Inquiry as the original place of publication. Readers are free to share these materials - as long as appropriate credit is given, a link to the license is provided, and any changes are indicated. 